\title{
Badania aktywnego siedziska maszynisty w pojazdach szynowych
}

\begin{abstract}
$W$ artykule zaprezentowano rezultaty badań eksperymentalnych aktywnego zawieszenia siedziska maszynisty elektrycznego zespotu trakcyjnego. Przedstawiono wykresy porównawcze przyspieszeń skutecznych drgań pionowych $w$ funkcji częstotliwości i prędkości jazdy. Otrzymane wyniki potwierdzity efektywność wibracji siedzisk z zawieszeniem aktywnym.
\end{abstract}

\section{Wstęp}

Parametry dynamiczne przestarzałego taboru kolejowego nie spełniają wymagań norm $\mathrm{w}$ zakresie wibracji [1,2 i 3]. Poziom wibracji w miejscu pracy drużyn trakcyjnych przekracza wartości dopuszczalne. Drgania oddziaływujące przez wiele lat na maszynistów są przyczyną wielu stanów chorobowych wśród tej grupy zawodowej.

Jedną $\mathrm{z}$ metod skutecznego ograniczania transmisji drgań do organizmu operatora pojazdu trakcyjnego jest stosowanie efektywnych układów wibroizolacji [6 i 7]. Opracowanie takich układów napotyka na wiele trudności m. in. związanych z faktem, że ich częstotliwości własne powinny być niskie wobec niskiego poziomu drgań środków transportu $(1 \div 10 \mathrm{~Hz})$. Trudności te pogłębiają się, jeżeli weźmie się pod uwagę niski poziom podstawowych częstotliwości rezonansowych ciała człowieka.

Stosowane dotychczas konstrukcje zawieszeń typu pasywnego w pojazdach trakcyjnych nie zapewniają wymaganej ochrony przed wibracjami i nie poprawiaja bezpieczeństwa jazdy. Dlatego podejmowane są próby zastępowania ich układami aktywnymi, które ze względu na małą częstotliwość własną skutecznie tłumią drgania i zwiększają komfort jazdy. Siedziska aktywne wobec nieliniowości zjawisk w układzie torpojazd szynowy są złożonymi obiektami sterowania, w których klasyczne algorytmy sterowania nie dają zadowalających rezultatów.

W takich sytuacjach jedną z metod poznawczych, mogących dostarczyć istotnych informacji o zachowaniu się obiektu rzeczywistego w eksploatacji, są badania eksperymentalne (doświadczalne).

Artykuł omawia wyniki badań eksperymentalnych aktywnego siedziska maszynisty elektrycznego zespołu trakcyjnego ER 2-690, przeprowadzonych w Państwowym Uniwersytecie Komunikacji w Omsku (Rosja) [5].

\section{Badania eksperymentalne}

Celem przeprowadzonych badań było porównanie właściwości wibroizolacyjnych doświadczalnego siedziska aktywnego z typowym siedziskiem maszynisty elektrycznego zespołu trakcyjnego ER 2-690, eksploatowanego powszechnie w przewozach pasażerskich na kolejach rosyjskich.
Dla realizacji tego celu w Państwowym Uniwersytecie Komunikacji w Omsku, wykorzystując doświadczenia zawarte w pracy [4] skonstruowano doświadczalne siedzisko maszynisty $\mathrm{z}$ serwomechanizmem elektrohydraulicznym, pełniącym rolę zawieszenia aktywnego (rys. 1) [5].

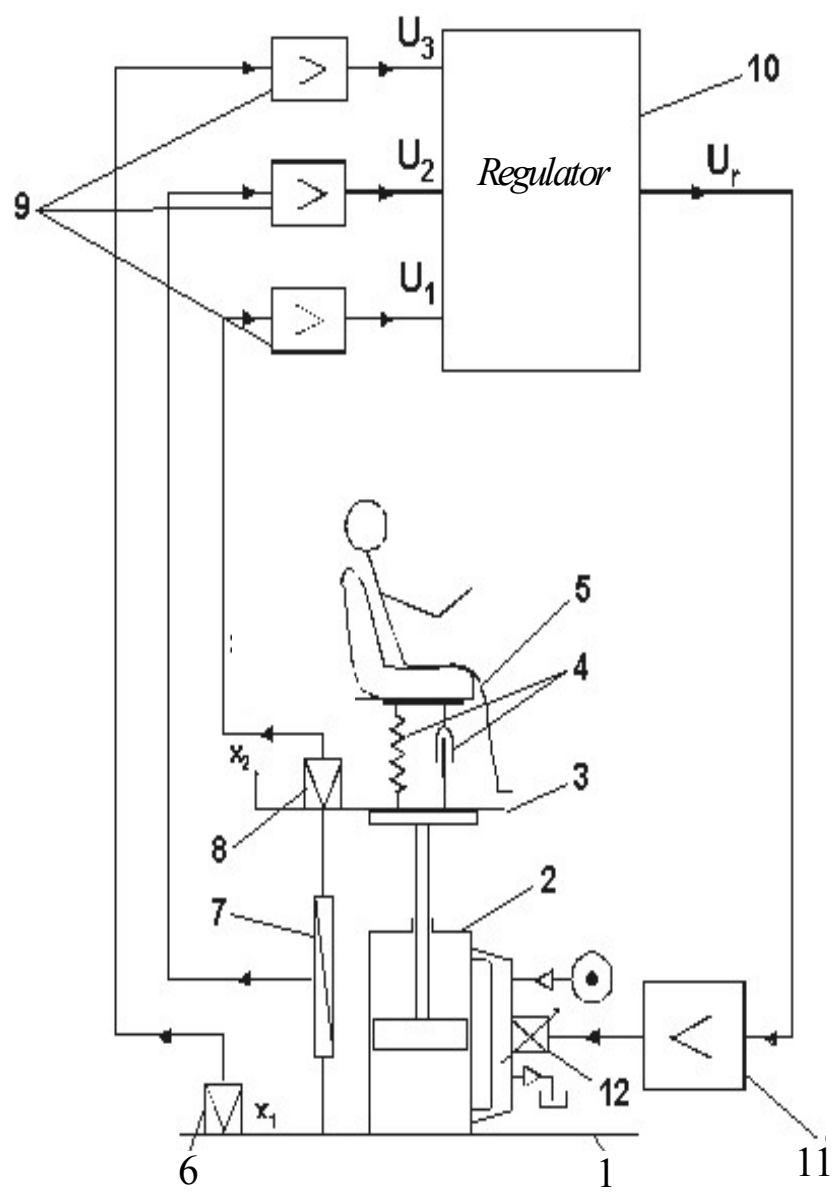

Rys. 1. Model aktywnego układu wibroizolacji siedziska maszynisty

1-nadwozie (podłoga kabiny), 2-cylinder, 3-platforma, 4sprężyna i thumik, 5-siedzisko maszynisty, 6-akcelerometr, 7-czujnik przemieszczeń, 8-akcelerometr, 9- wzmacniacze, 10-regulator, 11-wzmacniacz, 12-serwozawór 
Układ ten posiada cylinder 2 umieszczony w nadwoziu 1 pojazdu szynowego. Tłok cylindra poruszający się w płaszczyźnie pionowej utrzymuje platformę $\mathbf{3}$, na której spoczywa siedzisko maszynisty 5, izolowane dodatkowo sprężyną i thumikiem hydraulicznym 4. Strumień oleju w cylindrze sterowany jest serwozaworem 12, wykorzystującym sygnały sterujące przechodzace przez wzmacniacz 11, wygenerowane przez regulator 10. Ponadto układ posiada niezbędne przetworniki pomiarowe: dwa akcelerometry $\mathbf{6}$ i 8 do pomiaru bezwzględnego przyspieszenia nadwozia $\ddot{x}_{1}$ i siedziska $\ddot{x}_{2}$ oraz czujnik 7 do pomiaru przemieszczenia względnego $\Delta=x_{2^{-}} x_{1}$.

W konstrukcji prototypu przyjęto, że wszystkie trzy pętle (rys.1), posiadają charakterystyki częstotliwościowe, zapewniające proporcjonalność napięć wyjściowych $u_{1}, u_{2}$ i $u_{3}$ do siły sterującej tłokiem:

$$
u_{1}=b_{1} \cdot \ddot{x}_{2}, u_{2}=b_{2} \cdot\left(x_{2}-x_{1}\right)=b_{2} \cdot \Delta, u_{3}=b_{3} \cdot \ddot{x}_{1}
$$

gdzie: $b_{1}, b_{2}$ i $b_{3}$ są stałymi charakteryzującymi dany czujnik.

Natężenie przepływu objętości cieczy w cylindrze $Q$ musi być $\mathrm{w}$ pierwszym przybliżeniu wyrażone zależnością liniową:

gdzie:

$$
Q=\dot{\Delta} \cdot A
$$

$\dot{\Delta}=\dot{\mathrm{x}}_{2}-\dot{\mathrm{x}}_{1}$ - prędkość tłoka względem cylindra,

$A$ - powierzchnia tłoka.

Ruchy tłoka w cylindrze będa dostatecznie wolnymi, jeżeli zależność pomiędzy napięciem sygnału sterującego $u_{r}$ a prędkością $\dot{\Delta}$ i przyśpieszeniem

$\ddot{\Delta}$ tłoka względem cylindra będzie liniowa :

$$
u_{r}=a_{01} \cdot \dot{\Delta}+a_{11} \cdot \ddot{\Delta}
$$

gdzie: $a_{01}$ i $a_{11}$ są stałymi prędkości i przyśpieszenia tłoka, zapewniającymi jego sterowalność przy różnych częstotliwościach drgań nadwozia pojazdu.

Podstawowym zadaniem rozpatrywanego układu jest bezzwłoczne thumienie pionowych wibracji siedziska maszynisty pojazdu szynowego. Jednostkowe napięcie sygnału sterującego $u_{r}$ jest liniową kombinacją napięć $u_{1}, u_{2}$ i $u_{3}$ oraz ich wartości całkowych:

$$
\begin{aligned}
& u_{r}=\left(u_{11}+u_{12}+u_{13}+u_{14}\right)+\left(u_{22}+u_{23}+u_{24}\right)+ \\
& +\left(u_{31}+u_{32}+u_{33}+u_{34}\right)
\end{aligned}
$$

Po wprowadzeniu stałych $b_{1}, b_{2}$ i $b_{3}$ równania (3) i (4) określają siły sterujące.

Oddzielając zmienne opisujące nadwozie $x_{2 j}$ od zmiennych opisujących serwomechanizm $x_{l j}$ można uzyskać następujące równanie ruchu układu:

$$
\begin{aligned}
& \left(a_{11}+b_{1} \cdot c_{11}\right) \cdot \ddot{x}_{2}+\left(a_{01}+b_{1} \cdot c_{11}+b_{2} \cdot c_{22}\right) \cdot \dot{x}_{2}+ \\
& +\left(b_{1} \cdot c_{13}+b_{2} \cdot c_{23}\right) \cdot x_{2}+\left(b_{1} \cdot c_{14}+b_{2} \cdot c_{24}\right) \cdot \int x_{2} \cdot d t= \\
& \left(a_{11}-b_{3} c_{31}\right) \ddot{x}_{1}+\left(a_{01}+b_{2} \cdot c_{22}-b_{3} \cdot c_{32}\right) \cdot \dot{x}_{1}+ \\
& +\left(b_{2} \cdot c_{23}-b_{3} \cdot c_{33}\right) \cdot x_{1}+\left(b_{2} \cdot c_{24}-b_{3} \cdot c_{34}\right) \cdot \int x_{1} \cdot d t
\end{aligned}
$$

Lewa strona równania (5) opisuje ruch amortyzatora liniowego, który przechodzi w stan równowagi po spełnieniu następujących warunków :

$$
\begin{aligned}
c_{31} b_{3} & =a_{11}, \\
c_{32} b_{3} & =a_{01}+c_{22} b_{2}, \\
c_{33} b_{3} & =c_{23} b_{2,} \\
c_{34} b_{3} & =c_{24} b_{2}
\end{aligned}
$$

Jeżeli warunki kompensacji (6) $\div(9)$ spełnione są równocześnie, to równanie ruchu platformy 3 ( rys. 1) ma postać:

$$
\begin{aligned}
& \left(a_{11}+b_{1} c_{11}\right) \cdot \ddot{x}_{2}+\left(a_{01}+b_{2} c_{22}\right) \cdot \dot{x}_{2}+b_{2} c_{23} x_{2}+ \\
& +b_{2} c_{24} \cdot \int x_{2} d t=0
\end{aligned}
$$

Z równania (10) wynika, że współczynnik tłumienia określony jest stałą $c_{22}$, częstotliwość własna - stałą $c_{23}$, zaś warunki kompensacji wymuszeń zewnętrznych zostaną osiaggnięte za pomocą regulacji stałych $c_{32}, c_{33} i c_{34}$. Spełnienie warunków kompensacji gwarantuje wymaganą stabilność układu wibroizolacji.

Do pomiaru przyspieszeń drgań wykorzystano system CONAN (rys. 2), przeznaczony do planowania eksperymentów, monitoringu, sterowania i analizy sygnałów w czasie rzeczywistym. Jego centralnym elementem jest komputer wraz $\mathrm{z}$ oprogramowaniem, który steruje pracą pozostałych elementów układu i dokonuje analizy oraz wizualizacji wyników pomiarów.

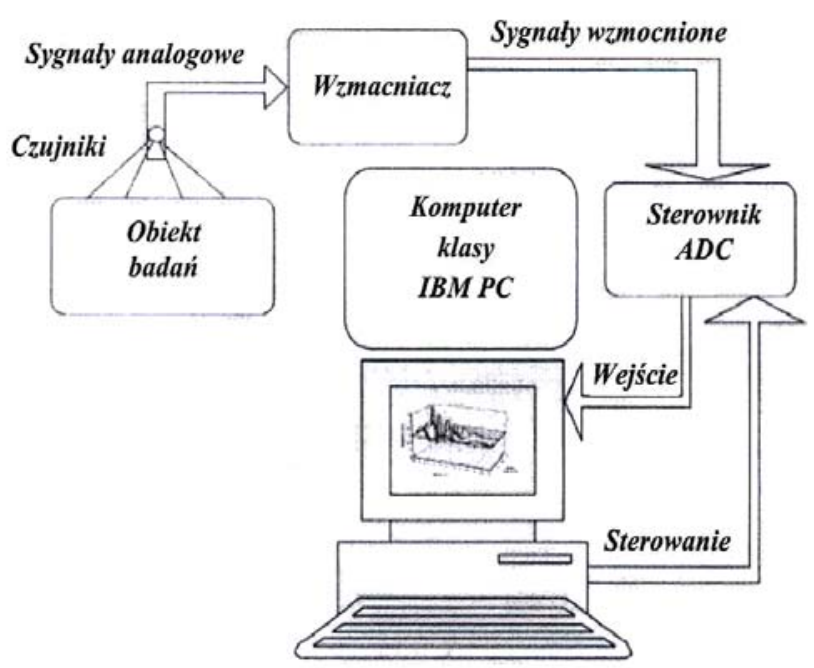

Rys.2. Schemat układu pomiarowego CONAN 
Ponadto kompleks CONAN posiada układ ADC, który przekształca sygnały analogowe w cyfrowe i jest urządzeniem typu wejście/wyjście, współpracującym z komputerem. Czujniki pomiarowe zainstalowane są bezpośrednio na badanych siedziskach maszynisty. Do rejestracji parametrów drgań wykorzystano zespół czterech czujników, które przekształcały mierzony parametr fizyczny w sygnał elektryczny i dostarczały pierwszych informacji o stanie badanego obiektu.

Miejsca rozmieszczenia czujników pomiarowych pokazano na rys. 3 .

Pomiary zgodnie z [3] trwały około 30 sekund i obejmowały sygnały drgań pionowych o częstotliwości powyżej $0,7 \mathrm{~Hz}$. Współczynnik sprężystości doświadczalnego siedziska aktywnego wynosił $1433 \mathrm{kN} / \mathrm{m}$, zaś wartość wskaźnika tłumienia drgań zmieniała się w granicach od 0,2 do 0,8 .

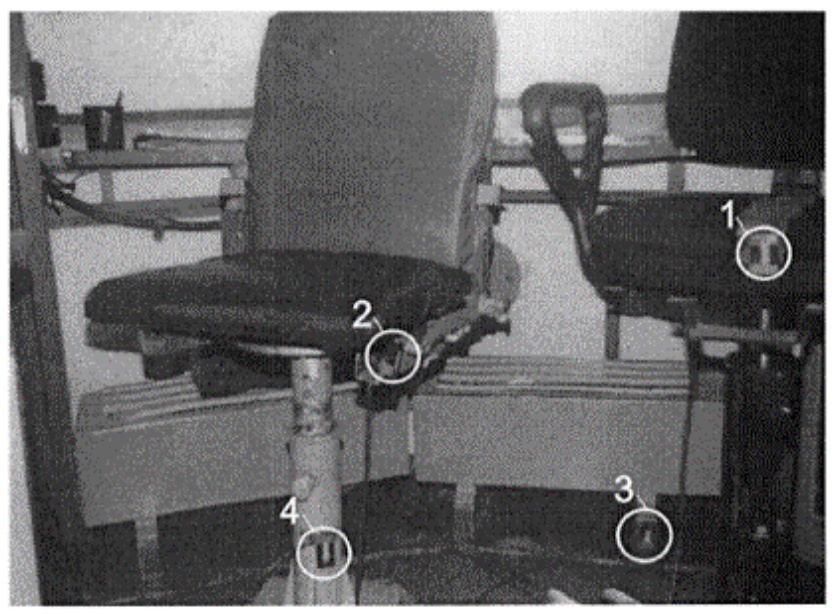

Rys. 3. Miejsca rozmieszczenia czujników pomiarowych 1- czujnik na siedzisku z zawieszeniem aktywnym, 2czujnik na siedzisku typowym, 3 i 4- czujniki na podłodze kabiny

\section{Wyniki pomiarów}

Wszystkie rejestrowane sygnały pomiarowe były zapisywane na dysku PC. Następnie za pomocą specjalistycznego oprogramowania wyznaczono przyspieszenia skuteczne (RMS) drgań pionowych w funkcji częstotliwości.

Na rys. 4 przedstawiono wykresy porównawcze przyspieszeń skutecznych (RMS) drgań pionowych mierzonych na podłodze kabiny maszynisty, siedzisku doświadczalnym i siedzisku typowym w zależności od prędkości jazdy.

$Z$ rys. 4 wynika, że wraz ze wzrostem prędkości jazdy następuje znaczny wzrost przyspieszeń drgań. Siedzisko typowe osiaga rezonans przy prędkości $65 \div 75 \mathrm{~km} / \mathrm{h}$. Zaś doświadczalne siedzisko aktywne w sposób zadowalający izoluje wibracje pionowe. W obszarze rezonansu maksymalne wartości przyśpieszeń skutecznych wynoszą odpowiednio $1,6 \mathrm{~m} / \mathrm{s}^{2}$ i
$0,72 \mathrm{~m} / \mathrm{s}^{2}$. W praktyce oznacza to, że efektywność wibroizolacji siedziska aktywnego jest 2,2 razy większa niż siedziska typowego.

$\mathrm{RMS}$
$\mathrm{m} / \mathbf{s}^{2}$

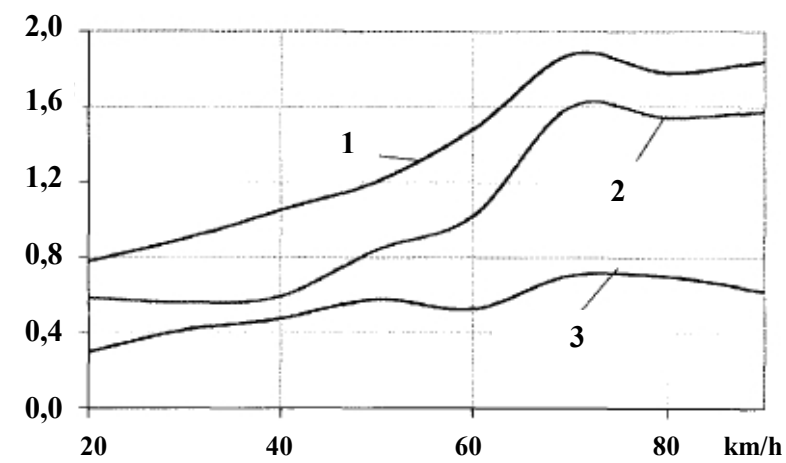

Rys. 4. Wykresy porównawcze przyspieszeń skutecznych RMS w zależności od prędkości jazdy

1-przyspieszenia mierzone na podłodze kabiny, 2- przyspieszenia mierzone na siedzisku typowym, 3- przyspieszenia mierzone na siedzisku aktywnym

$\mathrm{Na}$ rys.5 pokazano wykresy porównawcze przyspieszeń skutecznych (RMS) drgań pionowych w zależności od częstotliwości oraz granicę zdolności do pracy maszynisty pojazdu szynowego.
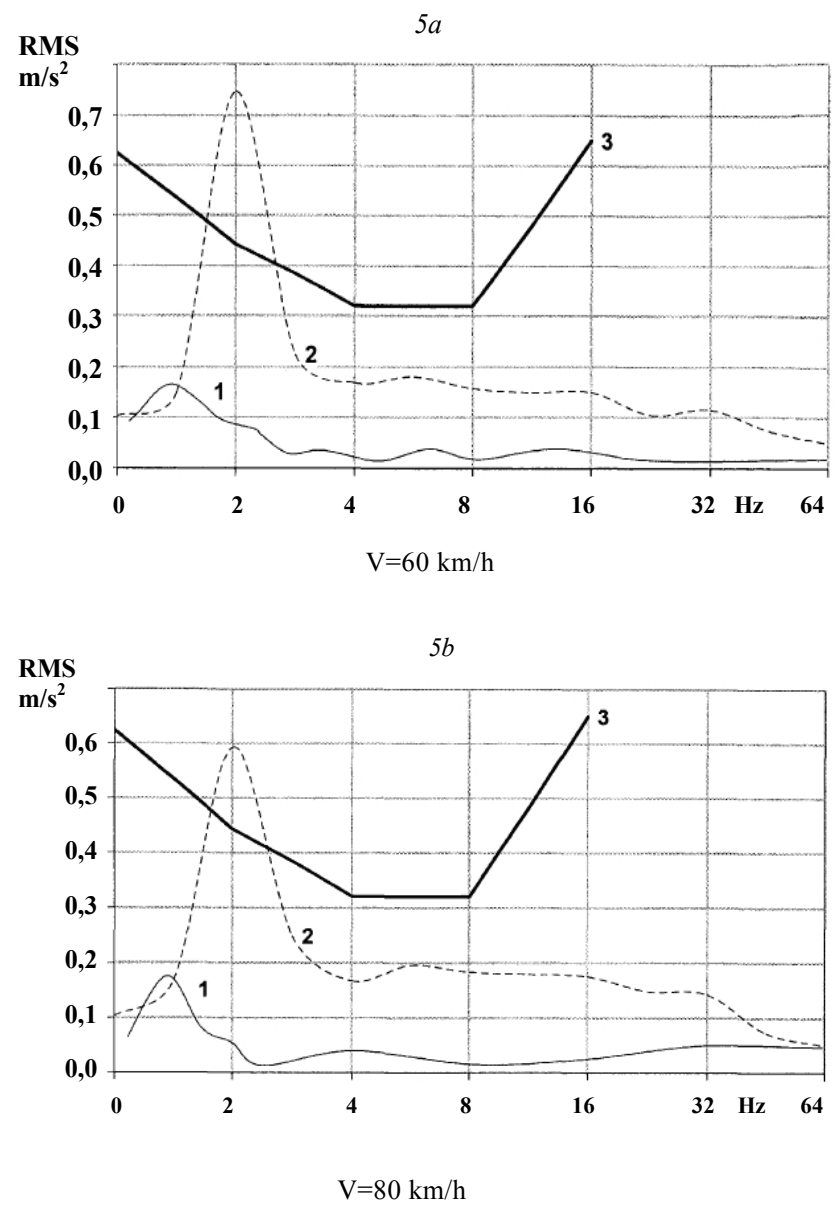


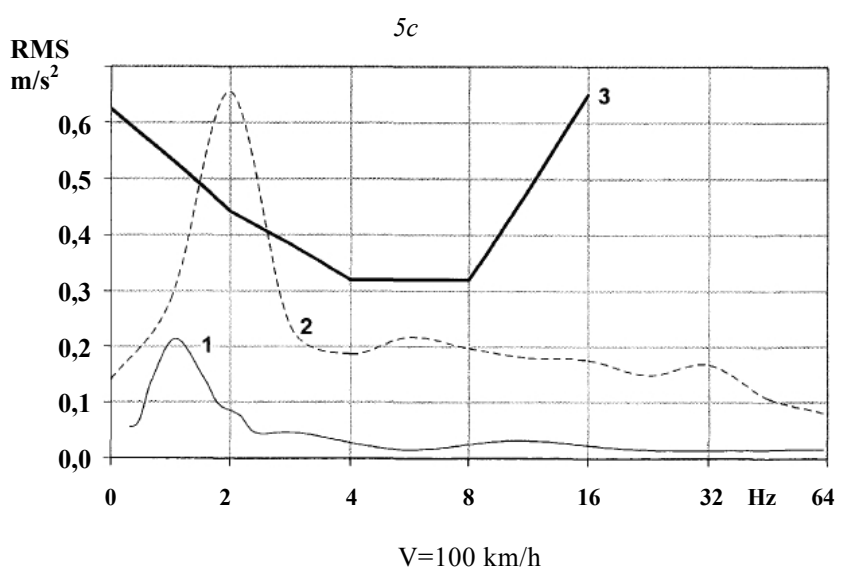

Rys.5. Wykresy porównawcze przyspieszeń skutecznych (RMS) w zależności od częstotliwości drgań dla różnych prędkości jazdy

1-siedzisko aktywne, 2- siedzisko typowe, 3- granica zdolności do pracy [3]

Z analizy zarejestrowanych sygnałów wynika, że w przypadku siedziska doświadczalnego granica zdolności do pracy nie została przekroczona w rozpatrywanym obszarze częstotliwości i prędkości jazdy.

W przypadku siedziska typowego, przy częstotliwości drgań własnych około $2,14 \mathrm{~Hz}$ i prędkości jazdy 60 $\mathrm{km} / \mathrm{h}$ występuje charakterystyczny pik rezonansowy, przekraczający o $44 \%$ granicę zdolności do pracy maszynisty. Zarejestrowane wzmocnienie rezonansowe pojawia się przy częstotliwości $2,2 \mathrm{~Hz}$, która praktycznie pokrywa się z częstotliwością drgań własnych nadwozia elektrycznego zespołu trakcyjnego,

Przeprowadzone pomiary wskazują jednoznacznie, że stosowanie aktywnego układu wibroizolacji powoduje zauważalne przesunięcie pików rezonansowych w stronę niskich częstotliwości występujących przy małych prędkościach jazdy. Doświadczalne siedzisko maszynisty w sposób zadowalający izoluje drgania i zapewnia komfort pracy przy częstotliwościach wyższych niż $0,7 \mathrm{~Hz}$.

\section{Wnioski}

Otrzymane wyniki pomiarów są bardzo obiecujące. Skonstruowane aktywne siedzisko zdecydowanie poprawia komfort pracy maszynisty pojazdu szynowego. Przy częstotliwości wymuszeń działających w kierunku pionowym równej $2 \mathrm{~Hz}$ przyspieszenia skuteczne zarejestrowane na tym siedzisku, mierzone w skali logarytmicznej, są o 12,8 dB mniejsze niż na typowym siedzisku pasywnym. Zaś przy częstotliwościach wymuszeń równych $1,3 \mathrm{~Hz}$ różnica pomiędzy badanymi siedziskami sięga $11,05 \mathrm{~dB}$, co oznacza, że przyspieszenia skuteczne zarejestrowane na siedzisku aktywnym są 2,5 razy mniejsze niż na siedzisku typowym.

Rezultaty przeprowadzonych badań eksperymentalnych będa wykorzystane $\mathrm{w}$ procesie budowy sformalizowanych reguł optymalnego sterowania aktywnym siedziskiem maszynisty.

\section{Literatura}

[1] Norma ISO 2631-1:Mechanical vibration and shock. Evaluation of human exposure to whole body vibration. Part 1: General Requirements. Second edition 1997-05-01.

[2] Polska Norma PN-91/S-04100. Drgania. Metody badań $i$ oceny drgań mechanicznych na stanowiskach pracy w pojazdach.

[3] ГОСТ 12.1.012.90. Вибрачионная безопасность. Общие требования. М.: Издателство стандартов, 1990.

[4]Hyuk Kim, Yong-San Yoon. :Semi-Active Suspension with Preview Using a Frequency-Shaped Performance Index. Veh. Syst. Dyn,24 (1995).

[5]Савелев Ю.Ф. Кресло машиниста электровоза с эффективной виброзащитной подвеской. Новые технологии - железнодорожному транспорту. Межвузовский сборник научных трудов. Омский Государственный Университет Путей Сообщения, Омск, 2002.

[6] Cisowski T.: Optymalne sterowanie uktadów wibroizolacji pojazdów szynowych $w$ obecności zakłóceń nieokreślonych. Pojazdy Szynowe $\mathrm{Nr}$ $4 / 2005$.

[7]Cisowski T.: Efektywny wibroizolator siedziska maszynisty. Pojazdy Szynowe Nr 1/2007. 